\title{
A case report on angioedema induced by levofloxacin: an unexpected occurrence
}

\author{
Haiya J. Sheth ${ }^{1}$, Shikha V. Sood ${ }^{1 *}$, Rushin P. Patel ${ }^{2}$, Supriya D. Malhotra ${ }^{1}$
}

${ }^{1}$ Department of Pharmacology, Smt. NHL MMC, Ahmedabad, Gujarat, India

${ }^{2}$ Intern, GCS Medical College, Ahmedabad, Gujarat, India

Received: 02 September 2017 Accepted: 25 September 2017

*Correspondence to:

Dr. Shikha V. Sood,

Email: shikhavsood@gmail.com

Copyright: (C) the author(s), publisher and licensee Medip Academy. This is an openaccess article distributed under the terms of the Creative Commons Attribution NonCommercial License, which permits unrestricted noncommercial use, distribution, and reproduction in any medium, provided the original work is properly cited.

\begin{abstract}
Angioedema is an abrupt swelling of the skin, mucous membrane, or both. It can be either food or drug induced. Drug induced Angioedema (allergic or nonallergic) is known with ACE inhibitors, NSAIDs, Beta-lactams. Levofloxacin is a well-tolerated, broad-spectrum fluoroquinolone commonly prescribed for urinary or respiratory tract infections. Common side effects with levofloxacin involve gastrointestinal tract. However, reports on Levofloxacin induced Angioedema are scarce. Hence, we report two cases of Levofloxacin induced Angioedema. In both the cases, patients developed swelling of face following ingestion of Tab. Levofloxacin $500 \mathrm{mg}$ orally BD on previous day. Drug was prescribed for urinary or respiratory infection. After a provisional diagnosis of Levofloxacin induced Angioedema by the dermatologist, both the patients were asked to withdraw the drug immediately. The reaction was treated with Inj. Avil (Pheniramine maleate) $1 \mathrm{cc}$ i.v. stat and Inj. Dexona (Dexamethasone) 2 cc i.v. stat in one patient whereas oral corticosteroid (Tab. Prednisolone 10mg orally OD with tapering dose) was used in second patient. Oral antihistaminics were also prescribed as per the necessity. Both patients recovered within 4-7 days. Both ADRs were uploaded via Vigiflow under Pharmacovigilance Programme of India (PvPI) with likely relationship between suspected drug and ADR. Incidence of Drug induced cutaneous ADRs (CADRs) in India is $2.85 \%$. Instances of hypersensitivity or anaphylactic reactions with fluoroquinolones are much lesser and milder than with NSAIDs or Beta-lactams. These reactions are associated with quinolone-specific Ig E. Existence of cross reactivity with quinolones is also high. This property is due to a similar ring (4-oxo-1, 4-dihydroquinoline ring) possessed by all fluoroquinolones. This allergic angioedema confined to the skin can be treated with antihistaminics or glucocorticoids.
\end{abstract}

Keywords: Cutaneous ADR, Cross-reactivity, Hypersensitivity

\section{INTRODUCTION}

All the drugs known to mankind have their own pros and cons. Pros include quick and effective therapeutic effects of drugs whereas among the cons include adverse drug reactions (ADRs) with varying severity, involving all organ systems including skin. The incidence of reported cutaneous ADRs (CADRs) in India is 2.85\%. ${ }^{1}$ These CADRs may range from mild to moderate Rashes, Angioedema to life threatening Stevens Johnson Syndrome and Toxic Epidermal Necrolysis. ADRs are an important cause of morbidity and mortality.
Angioedema is an abrupt swelling of the skin, mucous membrane, or both including respiratory and gastrointestinal tracts. ${ }^{2}$ It can be either food or drug induced. Drug-induced angioedema is a known complication with the use of angiotensin-converting enzyme (ACE) inhibitors, NSAIDs, Antimicrobials (beta lactams and quinolones up to some extent). ${ }^{3}$ The hypersensitivity reactions to fluoroquinolones are rare with an incidence of $0.4 \%$ to $2 \% .{ }^{4}$ Reports on angioedema induced by fluoroquinolones like Levofloxacin are relatively scarce. 
Levofloxacin is a well-tolerated, broad-spectrum fluoroquinolone prescribed commonly for the treatment of urinary tract infections and chest infections. The most common adverse effects with Levofloxacin involve gastrointestinal system (nausea, vomiting) or central nervous system (headache, seizures). Occasionally, patients may also end up with serious hypersensitivity and/or anaphylactic reactions requiring an immediate medical treatment.

Here, we present two cases of drug induced angioedema with levofloxacin being the suspected drug.

\section{CLINICAL CASE DETAILS}

\section{Case 1: Report id $=2017-05846$}

A 45 years old male patient presented to the Skin OPD at our setup with chief complaints of swelling of face (eyes and lips) since morning. It had developed following the ingestion of Tab. Levofloxacin $500 \mathrm{mg}$ orally BD on the previous day, prescribed for urinary tract infection for 2 days along with Tab. Paracetamol $500 \mathrm{mg}$ orally sos.

\section{Case 2: Report id $=2017-13727$}

An 18 years old female patient presented to the Skin OPD at our setup with chief complaints of swelling of face (eyes, lips, tongue) and hives over face, forearms, abdomen and back for 1 day. It had developed following the ingestion of Tab. Levofloxacin $500 \mathrm{mg}$ orally BD on the previous day, prescribed for upper respiratory infection for 3 days. Patient had history of ingestion of Tab. Amoxyclav (Amoxicillin 500mg + Clavulanic Acid $125 \mathrm{mg}$ ) orally BD 1 month ago, prescribed for a similar complaint.

In both cases, a provisional diagnosis of Levofloxacin induced Angioedema was made by the dermatologist and the patients were asked to discontinue Tab. Levofloxacin. A list of drugs commonly known to cause ADRs was also given to both to prevent future episodes. An appropriate medical management for Angioedema was started immediately. In case 1, patient was treated with Inj. Avil (Pheniramine maleate) $1 \mathrm{cc}$ i.v. stat; Inj. Dexona (Dexamethasone) 2 cc i.v. stat; Inj. MVBC (multivitamin B-complex); Tab. Levocetirizine $5 \mathrm{mg}$ orally BD for 5 Days. The patient's symptoms were relieved within 3-4 days. In case 2, patient was treated with oral steroid short course of Tab. Omnacortil (Prednisolone) 10mg orally OD tapering over 10 days; Tab. Levocetirizine $5 \mathrm{mg}$ orally BD for 10 days. She recovered within 1 week.

Here, there is a Likely/Probable causal relationship between the suspected drug and angioedema according to WHO-UMC criteria for Causality Assessment. Both these cases were also reported to the nearest ADR Monitoring Centre and uploaded via Vigiflow Base under Pharmacovigilance Programme of India (PvPI).

\section{DISCUSSION}

In our study, ADR in concern is Angioedema induced by Levofloxacin. These ADRs are commonly encountered in all the departments of hospital. In context to cutaneous ADRs, skin is second or third commonly involved system. In a study done by Patel TK et al, the incidence of CADRs among inpatient and outpatient settings are 82.59/1000 cases and 8.72/1000 cases respectively. ${ }^{5}$ These figures point towards the fact that incidence of Drug induced CADRs is notable and that each ADR needs to be noted.

Levofloxacin is a $3^{\text {rd }}$ generation fluoroquinolone which acts by inhibition of bacterial deoxyribonucleic acid (DNA) gyrase. It is an active levo (s) isomer of ofloxacin having improved activity against Strep. pneumoniae. and some other gram-positive and gram-negative bacteria. ${ }^{6}$ Since it is well-tolerated with a broad-spectrum activity, it is one of the most commonly prescribed fluoroquinolones for urinary and respiratory tract infections. ${ }^{7}$ Also owing to its easy availability, they are commonly self-prescribed or prescribed by the chemist too, thus leading to their abuse.

Literature states that instances of hypersensitivity or anaphylactic reactions with fluoroquinolones are much lesser and milder than with NSAIDs or Beta-lactams, thus not requiring hospitalization in most of the cases. For ofloxacin or its s-isomer levofloxacin, the most common adverse reactions involve gastrointestinal tract, with 3$17 \%$ of patients reporting mostly mild nausea, vomiting, and/or abdominal discomfort. ${ }^{7}$

However, hypersensitivity reactions to quinolones are rare which include rashes, urticaria, angioedema, anaphylaxis. These reactions have been associated with quinolonespecific Ig E. ${ }^{8}$ An ADR due to hypersensitivity to any drug has a genetic predisposition and have higher incidence in individuals with a history of atopy, family history of drug allergy and the presence of Human Leukocyte AntigenB22 (HLA-B22). ${ }^{4}$ Literature also mention the existence of cross reactivity with quinolones. Some studies conclude that the level of cross-reactivity between quinolones is high and that if a patient is allergic to one agent of the group, then all quinolones should be avoided. ${ }^{9}$ This property is due to a similar ring (4-oxo-1, 4dihydroquinoline ring) possessed by all fluoroquinolones with fluorine attached at position $6 .{ }^{10}$ However, skin testing for cross-reactivity among quinolones like prick test, patch test, histamine release test isn't considered reliable due to false positive results. The only definitive test to diagnose quinolone-induced immediate hypersensitivity is a challenge with the drug itself. ${ }^{8}$ But the risk of fatality on challenge of drug always persists. So, even though challenge or skin testing is a possible option, best is to contraindicate quinolones in such patients.

Angioedema has a wide range of aetiology. Broadly, causes are classified into two categories - allergic or nonallergic. Drug induced Angioedema of non-allergic origin is commonly seen with angiotensin converting enzyme 
(ACE) inhibitors. For allergic aetiology of drug induced Angioedema, the culprit drugs are commonly NSAIDS, beta-lactams, contrast media and to a smaller extent, quinolones. The prevalence of hypersensitivity reactions induced by NSAIDs and Beta-lactams is $0.1 \%-0.3 \%$ and $1 \%-10 \%$ respectively. ${ }^{11,12}$ But reports on incidence of angioedema induced by quinolones are sparse. Allergic variety of angioedema is $\mathrm{Ig} \mathrm{E}$ mediated i.e. Type 1 hypersensitivity. This allergic angioedema confined to the skin can be treated with antihistaminics or glucocorticoids. ${ }^{11}$

In this case report, both the cases and antihistaminics were non-serious and managed well with corticosteroids. However, angioedema if not treated, can lead to laryngeal oedema thus resulting in life-threatening or fatal consequences. ${ }^{13}$

Thus, the broad-spectrum activity as well as easy oral administration of levofloxacin and other quinolones has led to their rampant use clinically thereby increasing the incidences of adverse reactions.

\section{CONCLUSION}

To prevent the incidences of such drug induced angioedema or any other ADRs, a detailed allergic history of the patient should be taken. They should also be counselled regarding the seriousness of ADRs, provided with Drug Lists for future references and called for followup visits. Thus, our treatment should be aimed at preventing similar episodes in the future in the same patient. This necessitates the meticulous, and judicious use of medicines in daily clinical practice.

Various ADR related workshops and conferences should be organized periodically under the Pharmacovigilance Programme of India (PvPI) with the main objective to create awareness among healthcare professionals. They should be educated regarding reporting of ADRs as well as morbidity and mortality rates of ADRs annually. ADR reporting should be made compulsory at all the healthcare facilities. The digital reporting of ADRs provides a database which benefits the health care professionals in their day-to-day clinical practice.

\section{ACKNOWLEDGEMENTS}

Authors would like to thank Dr. Pankaj R. Patel, Dean, Smt. NHL Medical College, Ahmedabad for his constant support and encouragement. Also authors would like to thank Department of Dermatology for their help and guidance.

\section{Funding: No funding sources}

Conflict of interest: None declared

Ethical approval: Not required

\section{REFERENCES}

1. Ghosh S, Acharya LD, Rao PG. Study and evaluation of the various cutaneous adverse drug reactions in Kasturba hospital, Manipal. Indian J Pharm Sci. 2006;68(2):212-5.

2. Kulthanan $\mathrm{K}$, Jiamton $\mathrm{S}$, Boochangkool $\mathrm{K}$, Jongjarearnprasert K. Angioedema: Clinical and Etiological Aspects. Clinical and Developmental Immunology. 2007:26438.

3. Drug-induced angioedema. 2017. In Wikipedia, The Free Encyclopaedia. Retrieved 19:04, July 13, 2017, Available https://en.wikipedia.org/w/index.php?title= Druginduced_angioedema\&oldid=784225258.

4. Rawal G, Yadav S, Kumar R, Wani UR. Ofloxacin Induced Angioedema: A Rare Adverse Drug Reaction. Journal of Clinical and Diagnostic Research: JCDR. 2016;10(11):FD03-4.

5. Patel TK, Thakkar SH, Sharma DC. Cutaneous adverse drug reactions in Indian population: A systematic review. Indian Dermatol Online J. 2014;5(S2):76-86.

6. Haripriya H, Sujala S, Das V. Levofloxacin Induced Angioedema: A Case Report. World J Pharm Sci. 2016;4(11):175-6.

7. Petri WA. Sulfonamides, TrimethoprimSulfamethoxazole, Quinolones, and Agents for Urinary Tract Infections. Goodman \& Gilman's The Pharmacological Basis of Therapeutics. $12^{\text {th }}$ Ed. McGraw-Hill; 2011:1463-1476.

8. Owens RC, Ambrose PG. Antimicrobial Safety: Focus on Fluoroquinolones. CID. 2005:41(2);144-55.

9. Lobera T, Audícana MT, Alarcón E, Longo N, Navarro B, Muñoz D. Allergy to Quinolones: Low Cross-reactivity to Levofloxacin. J Investig Allergol Clin Immunol. 2010;20(7):607-11.

10. Anovadiya AP, Barvaliya MJ, Patel TK, Tripathi CB. Cross sensitivity between ciprofloxacin and levofloxacin for an immediate hypersensitivity reaction. Journal of Pharmacology \& Pharmacotherapeutics. 2011;2(3):187-8.

11. Jenny A, Van Amburgh. Drug-Induced Angioedema. Medscape. July 08, 2016. Available at: http://www.medscape.com/viewarticle/865745.

12. Benzylpenicillin. Martindale: The Complete Drug Reference; 36 ${ }^{\text {th }}$ Ed. Pharmaceutical Press; 2009:213.

13. Inomata $\mathrm{N}$. Recent Advances in Drug-Induced Angioedema. Allergolint. 2012;61(4):545-57.

Cite this article as: Sheth HJ, Sood SV, Patel RP, Malhotra SD. A case report on angioedema induced by levofloxacin: an unexpected occurrence. Int $\mathrm{J}$ Basic Clin Pharmacol 2017;6:2749-51. 